\title{
Retrospective analysis of older travellers attending a specialist travel health clinic
}

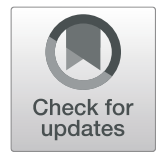

Milad Darrat ${ }^{{ }^{*}}$ (D) and Gerard T. Flaherty ${ }^{1,2}$

\begin{abstract}
Background: Older people represent a significant proportion of overseas travellers. The epidemiology of older international travellers is not well described in the literature. This study aims to identify demographics, travel characteristics and the medical profile of older travellers seeking pre-travel health advice in a specialist travel medicine clinic.

Methods: Records of travellers aged 60 years and older attending the Tropical Medical Bureau clinic in Galway, Ireland between 2014 and 2018 were examined. Descriptive and inferential analysis of data was performed.
\end{abstract}

Results: A total of 337 older travellers sought pre-travel health advice during the study period. The mean age of the cohort was $65.42( \pm 10)$ years. Most of the travellers $(n=267,80 \%)$ had at least one travelling companion. Nearly half of older travellers $(n=155,46.8 \%)$ were travelling with a single companion. Tourism was the main reason for travel for the majority $(n=260,77.6 \%)$, followed by visiting friends and relatives (VFR) $(n=23,6.9 \%)$ travellers. The mean interval remaining before the planned trip was $4.36( \pm 2)$ weeks, and the mean duration of travel was $3.16( \pm 1)$ weeks. The most popular single country of destination was India with 33 (9.8\%) visitors, and South East Asia was the most popular region with 132 (39.2\%) older travellers. The majority of travellers ( $n=267,79.2 \%$ ) had a documented pre-existing medical condition. The most commonly reported medical conditions were hypertension $(n=26,7.7 \%)$, dyslipidaemia $(n=18,5.3 \%)$, diabetes mellitus ( $n=12,3.5 \%)$, insect bite sensitivity $(n=11,3.3 \%)$, and hypothyroidism $(n=9,2.6 \%)$. Antihypertensive agents ( $n=32,9.4 \%)$ and statins $(n=24,7.1 \%)$ were the most frequently used medications. Typhoid $(n=112,33.2 \%)$ and hepatitis $\mathrm{A}(n=84,24.9 \%)$ were the most common vaccinations administered to older travellers at the clinic.

Conclusions: This study provides an insight into the demographics, travel characteristics, and medical profile of elderly travellers seeking advice at a large travel clinic in Ireland. A wide range of travel destinations, diseases and medication use was reported among this group of travellers, which may enable travel medicine physicians to provide more tailored advice and to more appropriately counsel older travellers.

Keywords: Older traveller, Travel medicine, Travel, Special group of travellers, Elderly

\section{Background}

The United Nations predicts that the global population will reach 10 billion by 2050 , nearly $20 \%$ of whom will be aged 60 years or older [1]. This increasing number of older people has implications for travel medicine. Older people represent a significant proportion of all travellers abroad. The World Tourism Organization anticipates that the number of

\footnotetext{
* Correspondence: m.darrat1@nuigalway.ie

'School of Medicine, National University of Ireland Galway, Galway, Ireland Full list of author information is available at the end of the article
}

international travellers will approach nearly 2 billion by 2030, with an estimated $15-30 \%$ of travellers aged 60 years or older [2]. Many older people have both the desire and capacity to take long overseas trips, especially if they feel well enough to do so [3]. The better quality of life, improved care of chronic illnesses, and financial stability after retirement have led to an increase in travel in this age group [4-8]. However, this can be challenging for health care professionals and services.

The older traveller group tends to have at least one chronic non-communicable disease [9]. Several studies

(C) The Author(s). 2019 Open Access This article is distributed under the terms of the Creative Commons Attribution 4.0 International License (http://creativecommons.org/licenses/by/4.0/), which permits unrestricted use, distribution, and 
have reported that the most common causes of death abroad were cardiovascular diseases, malignancies and trauma while infectious diseases were responsible for less than $10 \%$ of traveller deaths abroad [9-14]. This information implies that underlying non-communicable diseases which occur commonly in the older age group should be optimised in advance of international travel. There are significant physiological and clinical differences between older and younger travellers [15]. Older travellers are at higher risk of travel-associated morbidity and mortality. This is because they are less able to adapt physiologically during journeys and less able to adjust to climatic extremes. This increases the risk of exacerbation of their chronic medical conditions and reduces older people's immune response to travel vaccines [15].

Chronic medication use and polypharmacy are common issues for older travellers. Co-morbid medical conditions such as hypertension, dyslipidaemia, diabetes mellitus and chronic obstructive pulmonary disease are often coexisting, and each requires a combination of medications [16]. Several studies have reported that long-term medication use could influence the travel duration and itinerary of younger travellers [16-18]. There was no comparison with the older traveller group in these studies. Nonetheless, it was determined that $10-60 \%$ of older travellers in a large cohort study were taking at least one chronic medication [19]. Adherence to polypharmacy during travel can be very difficult as a result of time zone changes and travel disruption. This can also lead to exacerbation of underlying medical conditions $[20,21]$.

Ageing is strongly associated with immunosenescence [22]. Many older people may have poor protection against certain infectious diseases [22]. It has been established that less than half of the 65 years and over population in the USA and Europe have demonstrable antibodies against diphtheria and tetanus [23]. Few studies have examined the vaccination status and vaccine effectiveness of elderly travellers [24, 25]. It has been reported that $30-50 \%$ of international travellers of different age groups will suffer accidental injury or seek medical advice during their trip [26]. The cost of travel health insurance for older travellers is typically more expensive than that for younger travellers because of an increased proportion of claims and more costly medical expenses and evacuation, particularly with pre-existing conditions. This can discourage some elderly travallers from purchasing travel insurance and undermine their travel health status [17, 27].

The epidemiology of older travellers, including their characteristics, travel destination, pre-existing medical conditions, use of chronic medication and their vaccination status has not been well addressed by the available literature. Within the European context, limited research has been published that addresses the demographic and clinical profiles of older individuals travelling abroad. In this study, we analysed demographic attributes, travel itinerary, health profile, pre-existing illness and use of chronic medications among a cohort of older travellers who sought pre-travel advice at a specialist travel medicine clinic.

\section{Methods}

\section{Patients and data source}

Patients of 60 years of age and older were identified as older travellers for the purpose of this study [28]. Pre-travel medical registration cards completed between 2014 and 2018 at the Tropical Medical Bureau (TMB), Galway, Ireland were examined. These records had been completed by patients immediately prior to their consultation. They included data on age, gender, nationality, occupation, number in travelling party, travel destination, purpose of travel, duration of travel, interval before date of departure, departure and return dates, duration of stay, medical history including any pre-existing conditions, chronic medications, allergies, vaccination history, and health insurance. The record also includes a panel, which allows travellers to select from a list of common medical conditions. The travel medicine physician verifies these data and adds information on any prescribed antibiotics, antimalarial agents, vaccines or other medications that were prescribed during the clinic visit.

\section{Data collection and statistical analysis}

Data were extracted from medical registration cards and entered into a Microsoft Excel Office 365 Version 1811 database. All entered data were de-identified and assigned corresponding codes. Countries and regions were categorised according to the United Nations Statistics Division [29]. Interval and duration of travel were recorded and quantified in weeks. Medical data were recorded and entered according to a standardised list of 556 possible disease diagnoses [30]. Some patients were assigned to more than one pre-existing medical condition. Numerical variables were analysed using mean and median while categorical variables were reported as frequencies and percentages. Differences between proportions were determined by using a Chi-square test and nonparametric variables were assessed using Wilcoxon-Mann Whitney test. $P$-values were reported for comparisons between the groups of specific interest, with a $p$-value $<0.05$ considered statistically significant. No comparison was made between the older traveller and younger traveller groups in our database.

\section{Results}

Of 7123 medical registration cards available, 337 (5\%) records related to travellers aged 60 years and over. The mean age of these travellers was $65.42( \pm 10)$ years. More than half of the traveller sample $(n=179,53.5 \%)$ were above 65 years of age with the remaining travellers 
$(n=155,46.4 \%)$ between 60 and 64 years. Just over half of the travellers were female $(n=180,53.8 \%)$. The majority of travellers were from Ireland ( $n=289,87.3 \%)$, and the United Kingdom $(n=28,8.4 \%)$. The remaining countries contributed about $4.2 \%(n=14)$ of the older travellers (Table 1).

Most of the travellers were planning to travel with someone during their index trip. Nearly half of them planned on travelling in a pair $(n=155,46.8 \%)$. The rest were going to travel in groups of between 3 and 11 persons. Only $70(21.1 \%)$ older persons planned to travel alone. Most travellers $(n=235,69.9 \%)$ in our sample were retired from active employment. Employees (teachers, administrators, accountants, health care professionals and social workers) comprised 19.7\% $(n=66)$ of older travellers.

Hotel accommodation was the most popular accommodation choice with $83 \%(n=279)$ of the travellers planned to choose this form of accommodation. About $2.4 \%(n=8)$ of the travellers were going to stay in hostel accommodation. Camping and cruise ships were going to accommodate $1.5 \%(n=5)$ each. About $4.5 \%(n=15)$ of travellers expressed their intention to stay in multiple forms of accommodation.

The most commonly cited purpose of travel was a holiday in $77.6 \%(n=260)$ of the group, followed by visiting friends or relatives (VFR) with $6.9 \%(n=23)$ travellers. Just $3.9 \%(n=13)$ of travellers were travelling on assignments. Only $1.5 \%(n=5)$ of travellers were planning to trek (Table 1). The mean interval between visiting the clinic and travel was $4.364( \pm 2)$ weeks. The majority of the travellers $(n=331,98.2 \%)$ sought pre-travel advice 1-7 weeks before their departure date. The mean duration of travel was 3.167 $( \pm 1)$ weeks. There was no significant association between the purpose of travel and the time remaining before departure $(p=0.8)$.

Most of the cohort $(n=243,72.3 \%)$ planned to travel to a single country, while $24 \%(n=81)$ were visiting $2-3$ countries. The remaining travellers $(n=11,3.3 \%)$ planned to visit more than three countries on a single trip. The most popular single country of destination was India for $9.8 \%(n=33)$ of older travellers. South Africa was the second most visited destination $(n=27,8 \%)$, followed by Vietnam $(n=25,7.45 \%)$, Brazil $(n=18$, $5.3 \%)$, and Thailand ( $n=16,4.7 \%)$ (Fig. 1). South East Asia was the most popular geographic region with $39.2 \%$ $(n=132)$ of travellers. South America and Eastern Africa were the second most visited regions with $11.9 \%(n=40)$ each, while Southern Africa and Western Africa received $8 \%(n=27)$ and $3.9 \%(n=13)$ of travellers, respectively (Fig. 2).

The majority of travellers ( $n=267,79.2 \%)$ had a documented pre-existing medical condition (Table 2). A total of
Table 1 Demographics and travel characteristics of older travellers

\begin{tabular}{|c|c|c|}
\hline Characteristics & Frequency $(N)$ & Proportion (\%) \\
\hline \multicolumn{3}{|l|}{ Age } \\
\hline Mean Age (Years) & 65.42 & \\
\hline $60-64$ years & 155 & 46.4 \\
\hline$>=65$ years & 179 & 53.5 \\
\hline Total & 334 & \\
\hline \multicolumn{3}{|l|}{ Gender } \\
\hline Male & 154 & 46.1 \\
\hline Female & 180 & 53.8 \\
\hline Total & 334 & \\
\hline \multicolumn{3}{|l|}{ Country of origin } \\
\hline Ireland & 289 & 87.3 \\
\hline UK & 28 & 8.4 \\
\hline USA & 6 & 1.8 \\
\hline Germany & 2 & 0.6 \\
\hline Ghana & 2 & 0.6 \\
\hline Philippines & 2 & 0.6 \\
\hline Poland & 1 & 0.3 \\
\hline UAE & 1 & 0.3 \\
\hline Total & 331 & \\
\hline \multicolumn{3}{|l|}{ Travel alone/accompanied } \\
\hline Alone & 70 & 21.1 \\
\hline With one & 35 & 10.5 \\
\hline With two & 155 & 46.8 \\
\hline With three & 18 & 5.4 \\
\hline Between 4 and 10 & 35 & 10.6 \\
\hline More than 11 & 18 & 5.4 \\
\hline Total & 331 & \\
\hline \multicolumn{3}{|l|}{ Occupation } \\
\hline Retired & 235 & 69.9 \\
\hline All Employees & 54 & 16.1 \\
\hline Constructors & 25 & 7.4 \\
\hline Medical Practitioners & 12 & 3.6 \\
\hline Others & 10 & 2.9 \\
\hline Total & 336 & 100 \\
\hline \multicolumn{3}{|l|}{ Accommodation } \\
\hline Hotel & 279 & 83.0 \\
\hline Hostel & 8 & 2.4 \\
\hline Camping & 5 & 1.5 \\
\hline Cruise & 5 & 1.5 \\
\hline Others & 19 & 5.7 \\
\hline Unknown & 5 & 1.5 \\
\hline Multiple & 15 & 4.5 \\
\hline Total & 336 & 100 \\
\hline
\end{tabular}


Table 1 Demographics and travel characteristics of older travellers (Continued)

\begin{tabular}{lll}
\hline Characteristics & Frequency $(N)$ & Proportion (\%) \\
\hline Purpose of travel & 12 & 3.6 \\
Business & 260 & 77.6 \\
Holiday & 13 & 3.9 \\
Assignment & 5 & 1.5 \\
Trekking & 23 & 6.9 \\
Visiting friends-relatives & 1 & 0.2 \\
Others & 4 & 1.1 \\
Unknown & 17 & 5.0 \\
Multiple & 335 & 100 \\
Total & & \\
\hline
\end{tabular}

65 different illnesses were declared on their medical registration cards by the travellers in this study. The most commonly reported medical condition was hypertension at $7.7 \%$ $(n=26)$, followed by dyslipidaemia with $5.3 \%(n=18)$, type 2 diabetes mellitus in $3.5 \%(n=12)$, insect bite sensitivity affecting 3.2\% $(n=11)$ and hypothyroidism $2.6 \%(n=9)$ of travellers. The remaining illnesses comprised less than $1 \%$ of the sample including mental condition with $0.29 \%(n=1)$. Travellers with no pre-existing medical condition represented only $(n=70,20.8 \%)$ of the older travellers. There was no significant correlation between the healthier travellers and their destination $(p=0.09)$. More than half of the travellers $(n=211,62.6 \%)$ reported that they are taking prescribed medications at the time of travel, while $36.8 \%(n=124)$ were not taking any chronic medication. Antihypertensive agents $(n=32,9.5 \%)$ and statins $(n=24,7.1 \%)$ were the most frequently reported medications. Thyroxine $(n=15,4.5 \%)$, inhalers $(n=9,2.7 \%)$, and Vitamin D/Calcium $(n=5,1.5 \%)$ were also frequently reported medications among the older travellers. Proton pump inhibitors (PPIs) at $0.3 \%(n=1)$ were among the least reported medications (Table 3).

Most travellers $(n=245,73.1 \%)$ had never received travel vaccines before their index clinic visit. Typhoid and hepatitis A were the most common vaccinations administered to travellers at the clinic in 33\% $(n=112)$ and $25 \%$ $(n=84)$ of travellers, respectively. DPT (Diphtheria/Polio/ Tetanus $)$ in $19 \%(n=65)$, yellow fever vaccine $(n=17$, $5 \%)$, rabies vaccine $(n=15,4.5 \%)$, quadrivalent meningococcal vaccine in $3.5 \%(n=12)$, hepatitis B vaccine in $2.9 \%$ $(n=10)$ and oral cholera vaccine in $2.9 \%(n=10)$ were the next most frequently prescribed vaccinations. Influenza $(n=4,1.1 \%)$ and Japanese encephalitis $(n=2,0.5 \%)$ were among the least frequently administered vaccines. Over a third ( $n=122,36.2 \%$ ) of the older travellers were prescribed an antimalarial agent during their clinic visit, with atovaquone-proguanil being the most commonly prescribed antimalarial drug $(n=120,35.6 \%)$ (Table 4).

\section{Discussion}

Our study is among the first of its kind to examine the demographics, travel characteristics and medical burden of older travellers in an attempt to help travel health professionals to provide more tailored pre-travel health advice. Most of the older travellers who visited the travel medicine clinic during the four-year period of data collection had at least one documented preexisting medical illness on their travel registration card. We found that $79 \%$ of travellers had a documented

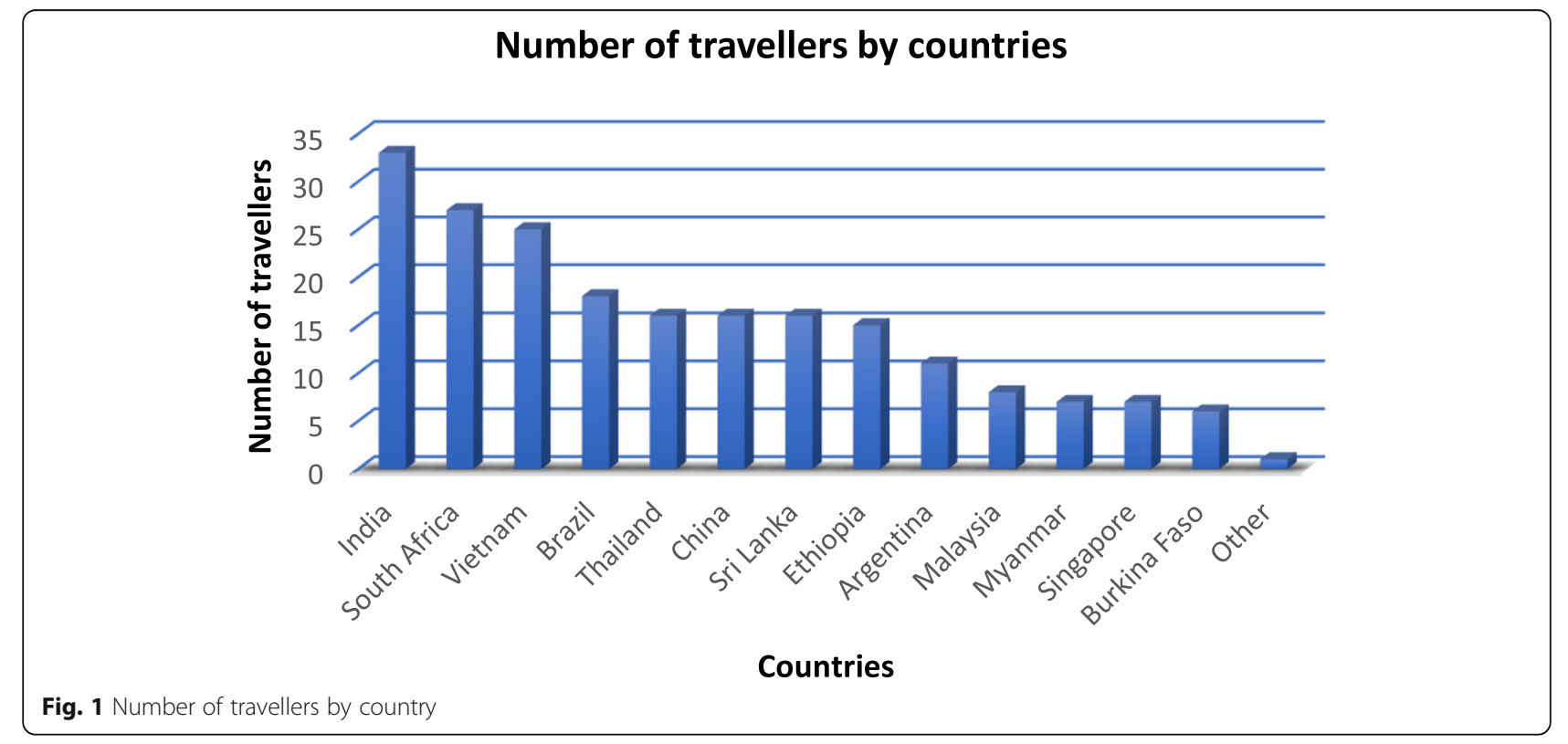




\section{Number of travellers by region}

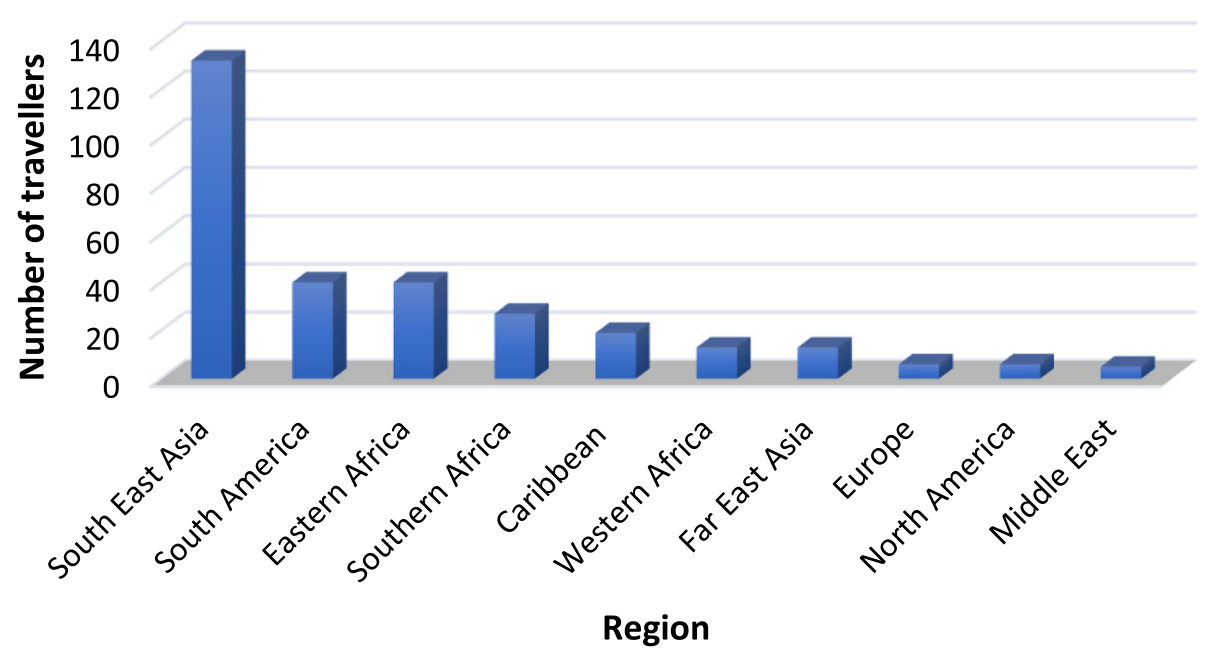

Fig. 2 Number of travellers by region

medical condition, which is higher than the $38-74 \%$ reported in previous studies [19, 31, 32].

Alon and colleagues [31] found that the mean age of elderly travellers was 65.6 years with a nearly equal sex distribution. They also found that the most common medical condition among their elderly travellers was hypertension, followed by hyperlipidaemia and cardiovascular disorders. However, the authors concluded that older travellers were more compliant with medical advice than younger travellers, therefore, they were at lower risk for illness exacerbation during travel. Similarly, Stienlauf et al. [19] found that over half of older travellers who attended a pre-travel clinic in Israel between 2005 and 2007 had at least one pre-existing medical condition, with the most frequent co-morbidities including hypertension (26\%), hyperlipaemia (23\%) and diabetes (7\%). The study concluded that the existence of a chronic medical condition does not have a significant impact on travel itinerary.
However, they concluded that chronic use of medications may have an impact on travel duration. Hochberg and colleagues [32] found that $74 \%$ of older travellers attending five clinics in the greater Boston area in the USA between March 2008 and July 2010 had co-morbid medical conditions. The authors recommended that travellers with complex medical histories may warrant assessment by an experienced travel medicine physician.

Our study findings are comparable to earlier reports, in relation to demographics and the most frequently occurring comorbidities. The mean age of our study sample was 65 years old, with the most commonly reported pre-existing illnesses being hypertension, dyslipidaemia and endocrine disorders. This is particularly noteworthy as the current findings may reflect the true medical illness burden of international travellers despite the relatively small sample size. The prevalence of these pre-existing conditions is not surprising.

Table 2 Pre-existing medical conditions of older travellers

\begin{tabular}{lll}
\hline Pre-existing medical condition & Frequency (N) & Proportion (\%) \\
\hline Yes & 267 & 79.2 \\
No & 70 & 20.7 \\
Total & 337 & 100 \\
Type of Condition & & 191 \\
$\quad$ Others (including chronic cardiac, pulmonary and allergic condition) & 26 & 56.6 \\
Hypertension & 18 & 7.7 \\
Dyslipidaemia & 12 & 3.3 \\
Type 2 diabetes mellitus & 11 & 3.5 \\
Insect bite sensitivity & 11 & 3.2 \\
Hypothyroidism & 9 & 2.6 \\
\hline
\end{tabular}


Table 3 Chronic medication use by older travellers

\begin{tabular}{lll}
\hline Medication Type & Frequency (N) & Proportion (\%) \\
\hline Others (including anticoagulants, antiplatelets, analgesics and immunosuppressants) & 124 & 36.7 \\
Antihypertensive agents & 32 & 9.4 \\
Statins & 24 & 7.1 \\
Thyroxine & 15 & 4.5 \\
Inhalers & 9 & 2.6 \\
Vitamin D/Calcium & 5 & 1.4 \\
\hline
\end{tabular}

Individuals with these conditions are often in a stable phase of the disease, thus may be more likely to choose to travel abroad [33, 34].

It was also of interest that the prevalence of diabetes mellitus among our elderly travellers was relatively low in this study. This may be due to the fact that diabetic travellers prefer to approach their own primary care doctor or endocrinologist, or perhaps they tend to avoid travelling overseas if they perceive their condition to pose too great a barrier to healthy travel. Several studies have shown that diabetic travellers are at higher risk of travel-associated illness, particularly infections and metabolic dysregulation [35-37], while other studies have reported more satisfactory outcomes for diabetics during travel abroad [38, 39].

The burden of psychiatric illness among our older travellers was also reported at a very low level (0.29\%), compared to an earlier report (1.5\%) [9]. This may be due to the low number of disclosures by travellers

Table 4 Prescribed vaccines and malaria chemoprophylaxis

\begin{tabular}{lll}
\hline Characteristics & Frequency $(N)$ & Proportion (\%) \\
\hline Previous vaccine & 87 & 25.8 \\
Yes & 245 & 72.7 \\
No & & \\
Vaccinations received at the clinic & 112 & 33.2 \\
Typhoid & 84 & 24.9 \\
Hepatitis A & 65 & 19.2 \\
DPT (Diphtheria/Polio/Tetanus) & 17 & 5.0 \\
Yellow fever & 15 & 4.5 \\
Rabies & 12 & 3.5 \\
Meningococcal & 10 & 2.9 \\
Hepatitis B & 10 & 2.9 \\
Oral cholera & 4 & 1.1 \\
Influenza & 2 & 0.5 \\
Japanese encephalitis & 0 & 0.0 \\
Pneumococcal & & 35.6 \\
Malaria chemoprophylaxis & 120 & 0.5 \\
Atovaquone-Proguanil & 2 & \\
Doxycycline & &
\end{tabular}

during their clinic registration. Any exacerbation of mental disorders during travel could present major challenges for the traveller, their companions as well as the local psychiatric health services at the host country which may be under resourced [40, 41].

The timing of the clinic visit before departure was 4 weeks in our older traveller cohort, which is adequate for travel physicians to provide appropriate intervention before travel. This interval allows the travel health specialists or general practitioners to counsel these highrisk travellers by optimising their pre-existing medical illness and titrating their medication dosage when necessary before their planned departure [42, 43].

In this study, India was the most popular country destination among elderly travellers, and Southeast Asia was the most popular single region despite its numerous travel health risks, including risks to personal safety, heat injury and vector-borne illnesses [44]. Our findings were similar to those of Swiss, Swedish and American studies $[9,44,45]$, while Senegal and Sub-Saharan Africa were the top travel destinations in French and Spanish studies $[46,47]$. One in ten of our travellers was travelling alone, which may put them at heightened risk of threats to their security and personal safety, as well as isolation from medical assistance in case of decompensation of their medical conditions [4].

More senior individuals taking chronic medication travel overseas; thus, travel medicine physicians may need to be more aware of issues surrounding geriatric medicine and polypharmacy [33]. Senior travellers frequently suffer from chronic diseases and take multiple medications; therefore, prescriptions by travel health specialists may lead to serious drug interactions or side effects. Few travellers in this study were taking anticoagulants; nonetheless, it is still a notable observation. Special consideration should be given to anticoagulant use during travel, particularly warfarin, which may give rise to potential drug-drug interactions in polypharmacy, or could have implications for malaria chemoprophylaxis, dietary factors and increased alcohol consumption, all of which could compromise bleeding control [48]. Travellers should also be encouraged to wear MedicAlert bracelets which state they are taking an anticoagulant $[48,49]$.

Travel to endemic vector-borne disease areas often necessitates the administration of vaccines and antimalarial 
chemoprophylaxis. Nearly the entire sample who visited the clinic were prescribed at least one vaccine and more that $30 \%$ received an antimalarial prescription. This may reflect the main reason for seeking consultation from the travel medicine clinic. This also implies that older travellers are more compliant in seeking pre-travel health care advice including vaccination and malaria chemoprophylaxis. This is in accordance with findings from other North American, European and Israeli studies [31, 50-53].

\section{Study limitations}

The data from this study were limited by the fixed structure of the medical registration card used in our clinic, which had been designed many years previously and was not modified during the research period. At the clinic visit, the traveller was asked to complete the card without direct guidance, hence, there is a possibility of recall bias. However, this was often corrected during the subsequent consultation. As the data were self-reported, social desirability bias cannot be ruled out as a limitation of this study. Furthermore, some questions in the registration cards, for example, the purpose of travel, were insufficiently defined. In Particular the designation "other" should be sub-categorised. Recording more detailed travel itineraries (eg, urban vs rural area visit) would also help to facilitate a more comprehensive risk assessment. The travel medicine physician recorded further additional information regarding the travellers' medical history on both their registration card and on a bespoke electronic medical record. Access to these electronic records was beyond the scope of the current research, however. Therefore, it is possible that the study population might have a higher burden of undocumented pre-existing medical conditions than what was apparent from the registration cards.

Our study findings may be extrapolated to older European travellers who seek pre-travel health advice. We believe that our study results provide insight into the characteristics, travel pattern, health conditions and pre-travel medical advice of a significant special group of travellers. Future prospective studies should investigate the travel risk-taking behaviour and care-seeking responses of older travellers during their travels abroad.

\section{Conclusions}

This study increases our understanding of the demographics, travel characteristics and medical profile of a selected vulnerable group of travellers seeking advice at a specialist travel medicine clinic. As Ireland has a high level of outbound international travellers, the study findings are also of significance in an international context. A wide range of travel destinations, diseases and medication use was reported among this group of travellers, which could enable travel medicine physicians to provide more tailored advice and to select an appropriate pre-travel health intervention.

\section{Acknowledgments}

We are grateful to Emma Conway, clinic manager at the Tropical Medical Bureau, Galway, for her assistance in retrieving patient records for the purposes of this study.

\section{Authors' contributions}

MD helped in designing the study, collected, analysed and interpreted the patient data and drafted the manuscript. GF was responsible for study conception, facilitated data acquisition and revised the manuscript critically. All authors read and approved the final manuscript.

\section{Funding}

None.

Availability of data and materials

The datasets during and/or analysed during the current study are available from the corresponding author.

Ethics approval and consent to participate

This was a non-interventional retrospective observational study, so no ethical approval was required.

Consent for publication

Not applicable.

Competing interests

The authors state that they have no conflicts of interest to declare.

\section{Author details}

${ }^{1}$ School of Medicine, National University of Ireland Galway, Galway, Ireland.

${ }^{2}$ School of Medicine, International Medical University, Kuala Lumpur, Malaysia.

Received: 28 May 2019 Accepted: 9 September 2019

Published online: 18 September 2019

References

1. United Nations, DESA. World population prospects: the 2015 revision, key findings and advance tables. New York: United Nations; 2015. Available at: https://esa.un.org/unpd/wpp/Publications/Files/Key_Findings_WPP_2015.pdf (Accessed 05 Jan 2019).

2. World Tourism Organization. Tourism towards 2030/global overview. Madrid: United Nations. Available at: http://www.e-unwto.org/doi/pdf/10.1 8111/9789284414024 (Accessed 18 Jan 2019.

3. Tung WS, Ritchie JB. Investigating the memorable experiences of the senior travel market: an examination of the reminiscence bump. J Travel Tour Mark. 2011;28(3):331-43.

4. Ramos-Sesma V, Gorgolas-Hernandez Mora M, Ramos-Rincon JM. The elderly traveller. Rev Clin Esp. 2018;218(8):426-34.

5. Hsu CH, Cai LA, Wong KK. A model of senior tourism motivations - anecdotes from Beijing and Shanghai. Tour Manag. 2007; 28(5):1262-73.

6. Jang SS, C-ME W. Seniors' travel motivation and the influential factors: an examination of Taiwanese seniors. Tour Manag. 2006;27(2):306-16.

7. Flaherty GT, Rossanese A, Steffen R, et al. A golden age of travel: advancing the interests of older travellers. J Travel Med. 2018;25(1):tay088.

8. Flaherty GT. Research on the move: the potential applications of mobile health technology in travel medicine. J Travel Med. 2016;23(6):taw061.

9. LaRocque RC, Rao SR, Lee J, et al. Global TravEpiNet: a national consortium of clinics providing care to international travelers-analysis of demographic characteristics, travel destinations, and pretravel healthcare of high-risk US international travelers, 2009-2011. Clin Infect Dis. 2011;54(4):455-62.

10. Brunette GW. CDC yellow book 2018: health information for international travel. Atlanta: Oxford University Press; 2017.

11. Heckmann JG, Stemper B, Ringwald J, et al. Economy class stroke syndrome. Cerebro Dis. 2004;17(1):88.

12. Tonellato DJ, Guse CE, Hargarten SW. Injury deaths of US citizens abroad: new data source, old travel problem. J Travel Med. 2009;16(5):304-10.

13. Darrat M, Flaherty G. Deaths of Irish civilians abroad: analysis of National Mortality Data, 2016-2018. Int J Trav Med Glob Helath. 2018;6(4):149-53. 
14. Connolly R, Prendiville R, Cusack D, et al. Repatriation of human remains following death in international travellers. J Travel Med. 2017;24(2):82.

15. Izaks GJ, Westendorp RG. III or just old? Towards a conceptual framework of the relation between ageing and disease. BMC Geriatr. 2003;3(1):7.

16. Eperon G, Chappuis F. Elderly travellers: review and advices. Rev Med Suisse. 2015;11(473):1028-32.

17. Lee TK, Hutter JN, Masel J, et al. Guidelines for the prevention of travelassociated illness in older adults. Trop Dis Travel Med Vaccin. 2017:3(1):10.

18. Baker L, Brink G, Lipschitz S, et al. The older Traveller: a guide for the health professional. 1st ed. Green Stone: South African Society of Travel Medicine; 2016.

19. Stienlauf S, Streltsin B, Meltzer E, et al. Chronic illnesses in travelers to developing countries. Travel Med Infect Dis. 2014;12(6):757-63.

20. Stienlauf S, Meltzer E, Kurnik D, et al. Potential drug interactions in travelers with chronic illnesses: a large retrospective cohort study. Travel Med Infect Dis. 2014;12(5):499-504.

21. Han CT, Flaherty G. Profile of travelers with preexisting medical conditions attending a specialist travel medicine Clinic in Ireland. J Travel Med. 2015; 22(5):312-7.

22. Hirokawa K, Utsuyama M, Kasai M, et al. Aging and immunity. Pathol Int. 1992;42(8):537-48.

23. Centers for Disease Control and Prevention. (CDC). Updated recommendations for use of tetanus toxoid, reduced diphtheria toxoid, and acellular pertussis (TDAP) vaccine in adults aged 65 years and older. Advisory committee on immunization practices (ACIP), 2012. Morb Mortal Wkly Rep. 2012;61(25):468.

24. Ericsson CD, Steffen R, Weller PF, et al. Travel vaccines and elderly persons: review of vaccines available in the United States. Clin Infect Dis. 2001;33(9):1553-6.

25. Jonker EF, Visser LG, Roukens AH. Advances and controversies in yellow fever vaccination. Ther Adv Vaccines. 2013;1(4):144-52.

26. Hill DR. The burden of illness in international travelers. N Engl J Med. 2006; 354(2):115-7.

27. Leggat PA, Leggat FW. Travel insurance claims made by travelers from Australia. J Travel Med. 2002;9(2):59-65.

28. Roebuck J. When does old age begin?: the evolution of the English definition. J Soc Hist. 1979;12(3):416-28.

29. United Nations. Composition of macro geographical (continental) regions, geographical sub-regions, and selected economic and other groupings. Available at: http://unstats.un.org/unsd/methods/m49/ (Accessed 02 Feb 2019).

30. Freedman DO, Weld LH, Kozarsky PE, et al. Spectrum of disease and relation to place of exposure among ill returned travelers. N Engl Med. 2006;354(2):119-30.

31. Alon D, Shitrit P, Chowers M. Risk behaviors and spectrum of diseases among elderly travelers: a comparison of younger and older adults. J Travel Med. 2010;17(4):250-5.

32. Hochberg NS, Barnett ED, Chen LH, et al. International travel by persons with medical comorbidities: understanding risks and providing advice. Mayo Clin Proc. 2013:88(11):1231-40.

33. Frizelle F. The older Traveller: a guide for the health professional. N Z Med J. 2018;131(1477):118-9.

34. Suh KN, Flaherty GT. The older traveler. In: Keystone J, Kozarsky P, Connor BA, et al., editors. Travel Medicine. 4th ed. London: Elsevier; 2019. p. 247-53.

35. Wieten RW, Leenstra T, Goorhuis A, et al. Health risks of travelers with medica conditions - a retrospective analysis. J Travel Med. 2012;19(2):104-10.

36. Driessen SO, Cobelens FG, Ligthelm RJ. Travel-related morbidity in travelers with insulin-dependent diabetes mellitus. J Travel Med. 1999;6(1):12-5.

37. Burnett JCD. Long- and short-haul travel by air: issues for people with diabetes on insulin. J Travel Med. 2006;13(5):255-60.

38. Baaten GG, Roukens AH, Geskus RB, et al. Symptoms of infectious diseases in travelers with diabetes mellitus: a prospective study with matched controls. J Travel Med. 2010;17(4):256-63.

39. Levy-Shraga $Y$, Hamiel U, Yaron M, et al. Health risks of young adult travelers with type 1 diabetes. J Travel Med. 2014;21(6):391-6.

40. Valk TH. Mental health issues of travelers. Travel Medicine (Fourth edition) London. 2019;12(5):463-7.

41. Seeman MV. Travel risks for those with serious mental illness. int J Trav Med Glob Health. 2016;4(3):76-81.

42. Gautret P, Gaudart J, Leder K, et al. Travel-associated illness in older adults (> 60 y). J Travel Med. 2012;19(3):169-77.

43. Flaherty GT, Chen B, Avalos G. Individual traveller health priorities and the pre-travel health consultation. J Travel Med. 2017;24(6):tax059.

44. Bühler $S$, Rüegg $R$, Steffen $R$, et al. A profile of travelers - an analysis from a large Swiss travel clinic. J Travel Med. 2014;21(5):324-31.
45. Angelin $\mathrm{M}$, Evengård $\mathrm{B}$, Palmgren $\mathrm{H}$. Travel and vaccination patterns: a report from a travel medicine clinic in northern Sweden. Scand J Infect Dis. 2011;43(9):714-20

46. Aubry C, Gaudart J, Gaillard C, et al. Demographics, health and travel characteristics of international travellers at a pre-travel clinic in Marseille, France. Travel Med Infect Dis. 2012;10(5-6):247-56.

47. Valerio L, Martínez O, Sabrià M, et al. High-risk travel abroad overtook lowrisk travel from 1999 to 2004: characterization and trends in 2,622 Spanish travelers. J Travel Med. 2005;12(6):327-31.

48. Lip GY, Leung LL, Schmader KE, et al. Anticoagulation in Elderly. Available at : https://www.medscape.com/viewarticle/460845 5 (Accessed on 03 Mar 2019).

49. Leung LL. Direct oral anticoagulants and parenteral direct thrombin inhibitors: Dosing and adverse effects: UpToDate Waltham. Available at: https://www.uptodate.com/contents/direct oral anticoagulants and parenteral direct thrombin inhibitors dosing and adverse effects (Accessed on 03 Apr 2019).

50. Hill DR. Health problems in a large cohort of Americans traveling to developing countries. J Travel Med. 2000;7(5):259-66.

51. Rack J, Wichmann O, Kamara B, et al. Risk and spectrum of diseases in travelers to popular tourist destinations. J Travel Med. 2005;12(5):248-53.

52. Winer $L$, Alkan $M$. Incidence and precipitating factors of morbidity among Israeli travelers abroad. J Travel Med. 2002;9(5):227-32.

53. Cooper MC. The elderly travellers. Travel Med Infect Dis. 2006;4(3-4):218-22.

\section{Publisher's Note}

Springer Nature remains neutral with regard to jurisdictional claims in published maps and institutional affiliations.
Ready to submit your research? Choose BMC and benefit from:

- fast, convenient online submission

- thorough peer review by experienced researchers in your field

- rapid publication on acceptance

- support for research data, including large and complex data types

- gold Open Access which fosters wider collaboration and increased citations

- maximum visibility for your research: over $100 \mathrm{M}$ website views per year

At $\mathrm{BMC}$, research is always in progress.

Learn more biomedcentral.com/submissions 